\title{
Escalation therapy in severe traumatic brain injury: how long is intracranial pressure monitoring necessary?
}

\author{
Pasquale Anania ${ }^{1}$ (D) - Denise Battaglini ${ }^{2,3} \cdot$ John P. Miller ${ }^{4}$ Alberto Balestrino ${ }^{1} \cdot$ Alessandro Prior ${ }^{1} \cdot$ \\ Alessandro D'Andrea ${ }^{1} \cdot$ Filippo Badaloni ${ }^{5} \cdot$ Paolo Pelosi $^{2,6} \cdot$ Chiara Robba $^{2,6} \cdot$ Gianluigi Zona $^{1,7} \cdot$ Pietro Fiaschi ${ }^{1,7}$
}

Received: 11 May 2020 / Revised: 29 September 2020 / Accepted: 11 November 2020 / Published online: 19 November 2020

(C) Springer-Verlag GmbH Germany, part of Springer Nature 2020

\begin{abstract}
Traumatic brain injury frequently causes an elevation of intracranial pressure (ICP) that could lead to reduction of cerebral perfusion pressure and cause brain ischemia. Invasive ICP monitoring is recommended by international guidelines, in order to reduce the incidence of secondary brain injury; although rare, the complications related to ICP probes could be dependent on the duration of monitoring. The aim of this manuscript is to clarify the appropriate timing for removal and management of invasive ICP monitoring, in order to reduce the risk of related complications and guarantee adequate cerebral autoregulatory control. There is no universal consensus concerning the duration of invasive ICP monitoring and its related complications, although the pertinent literature seems to show that the longer is the monitoring maintenance, the higher is the risk of technical issues. Besides, upon $72 \mathrm{~h}$ of normal ICP values or less than $72 \mathrm{~h}$ if the first computed tomography scan is normal (none or minimal signs of injury) and the neurological exam is available (allowing to observe variations and possible occurrence of new-onset pathological response), the removal of invasive ICP monitoring can be justified. The availability of non-invasive monitoring systems should be considered to follow up patients' clinical course after invasive ICP probe removal or for substituting the invasive monitoring in case of contraindication to its placement. Recently, optic nerve sheath diameter and straight sinus systolic flow velocity evaluation through ultrasound methods showed a good correlation with ICP values, demonstrating their potential role in place of invasive monitoring or in the early weaning phase from the invasive ICP monitoring.
\end{abstract}

Keywords TBI $\cdot$ Brain injury $\cdot$ ICP $\cdot$ Monitoring $\cdot$ Duration $\cdot$ Weaning

Pasquale Anania

pas.anania@gmail.com

1 Department of Neurosurgery, Policlinico San Martino Hospital, IRCCS for Oncology and Neuroscience, Genoa, Italy

2 Anesthesia and Intensive Care, Policlinico San Martino Hospital, IRCCS for Oncology and Neuroscience, Genoa, Italy

3 Department of Medicine, University of Barcelona, Barcelona, Spain

4 Louisiana State University, Health Sciences University, New Orleans, LA, USA

5 Division of Neurosurgery, IRCCS Institute of Neurological Sciences of Bologna, Bologna, Italy

6 Department of Surgical Sciences and Integrated Diagnostic (DISC), University of Genoa, Genoa, Italy

7 Department of Neurosciences, Rehabilitation, Ophthalmology, Genetics and Maternal And Children (DINOGMI), University of Genoa, Genoa, Italy

\section{Introduction}

Traumatic brain injury (TBI) is defined as sudden damage that occurs to the brain after a traumatic event. TBI is often followed by an elevation of intracranial pressure (ICP) due to intracranial hemorrhage, cerebral edema, or hydrocephalus which results in the reduction of cerebral perfusion pressure (CPP) and ultimately brain ischemia $[29,61]$.

Invasive intracranial pressure (I-ICP) monitoring is recommended by international guidelines and supported by international studies $[10,13,14,16,29,59,61,62]$ to reduce the incidence of secondary brain injury [16]. I-ICP monitoring is suggested for patients with TBI and abnormalities on computed tomography (CT), for selected patients with a normal CT scan but with clinical signs suggestive of secondary brain injury, and for those patients in whom a neurological examination is not available. The accepted ICP threshold for starting treatment is $>$ $22 \mathrm{mmHg}[10,61]$. In the event of ICP elevation, a CT scan should be repeated in order to exclude surgically treatable lesions 
before escalating other therapies. Therefore, I-ICP monitoring is crucial to guide the staircase approach (Fig. 1), which includes a step-by-step increase in treatment aggressiveness to control ICP, with more aggressive treatment reserved to specific cases when more conservative treatments have failed [13, 16, 29, 59]. A risk versus benefit analysis concerning the insertion of an ICP monitoring probe should be taken into account because of the risk of hemorrhage (1-7\%) and infection (1-27\%) [61]. Moreover, it is questioned whether ICP monitoring is accurate after prolonged monitoring time $[5,48,49]$. Taken together, these findings suggest that the early positioning of I-ICP is fundamental in those patients who fulfill the criteria for monitoring to reduce secondary brain injury; however, questions remain in borderline situations when the patients might not benefit from monitoring and could be at risk for probe-related complications.

The aim of our narrative review is to briefly describe the current practice concerning the I-ICP monitoring, ICP management, the possible duration of invasive ICP maintenance to reduce the risk of ICP probe-related complications, and the indications for non-invasive ICP monitoring. For this purpose, we performed a literature search on PubMed, using the following terms: (ICP OR "intracranial pressure") AND (timing OR removal OR remove OR weaning) (Fig. 2). Titles and abstracts were analyzed and independently assessed for eligibility by three authors (PA, DB, AB); disagreements were resolved by discussion and, if required, input from a third author (AP) (Fig. 2).

\section{The staircase approach}

The escalation treatment for the management of intracranial hypertension has become the standard of care in intensive care unit (ICU) [10, 16, 61] (Fig. 1). In 2019, the Seattle
International Severe Traumatic Brain Injury $[12,27]$ developed a management algorithm for TBI through evidencebased treatment protocols for helping physicians in the management of TBI patients with I-ICP monitoring [27]. The first step of this approach includes analgesia and sedation, which are mandatory to treat those cases of hypertension related to pain and agitation, to prevent seizures, and to avoid asynchronies between the patient and the mechanical ventilator. Hypotension is the most common risk related to deep sedation which belies the importance of maintaining a normal intravascular volume $[10,16,43,61]$. Continuous CSF drainage may be useful if an external ventricular drainage is placed, although the evidence regarding its efficacy on long-term intracranial hypertension control is not strong [10]. In fact, intraventricular devices for I-ICP detection are catheters with a transducer (fiber-optic strain gauge or pneumatic sensor) placed into the cerebral ventricular system and connected to an external monitoring system, which allow the drainage of CSF through the catheter in case of intracranial hypertension, facilitating the ICP control [42]. The use of lumbar CSF drainage has to be avoided for the risk of tonsillar herniation [12, 61]. Hyperosmolar therapies reduce ICP elevation by increasing plasma osmolarity, moving free water from the brain to the blood circuit, due to the gradient between the two compartments across the blood-brain barrier [54]. Besides, mannitol non-bolus continuous infusion is not recommended [27]. Another step includes hyperventilation with induced blood hypocarbia with partial pressure of carbon dioxide $\left(\mathrm{PaCO}_{2}\right)$ below $35-38 \mathrm{mmHg}$ [12] which results in vasoconstriction followed by CBF and ICP reduction. It should be noted that this maneuver carries the risk of brain ischemia, making the use of advanced monitoring systems of cerebral oxygenation (e.g., monitoring of jugular bulb and brain tissue oxygenation) essential [60]. Moderate hypothermia $\left(32-34{ }^{\circ} \mathrm{C}\right)$ is another

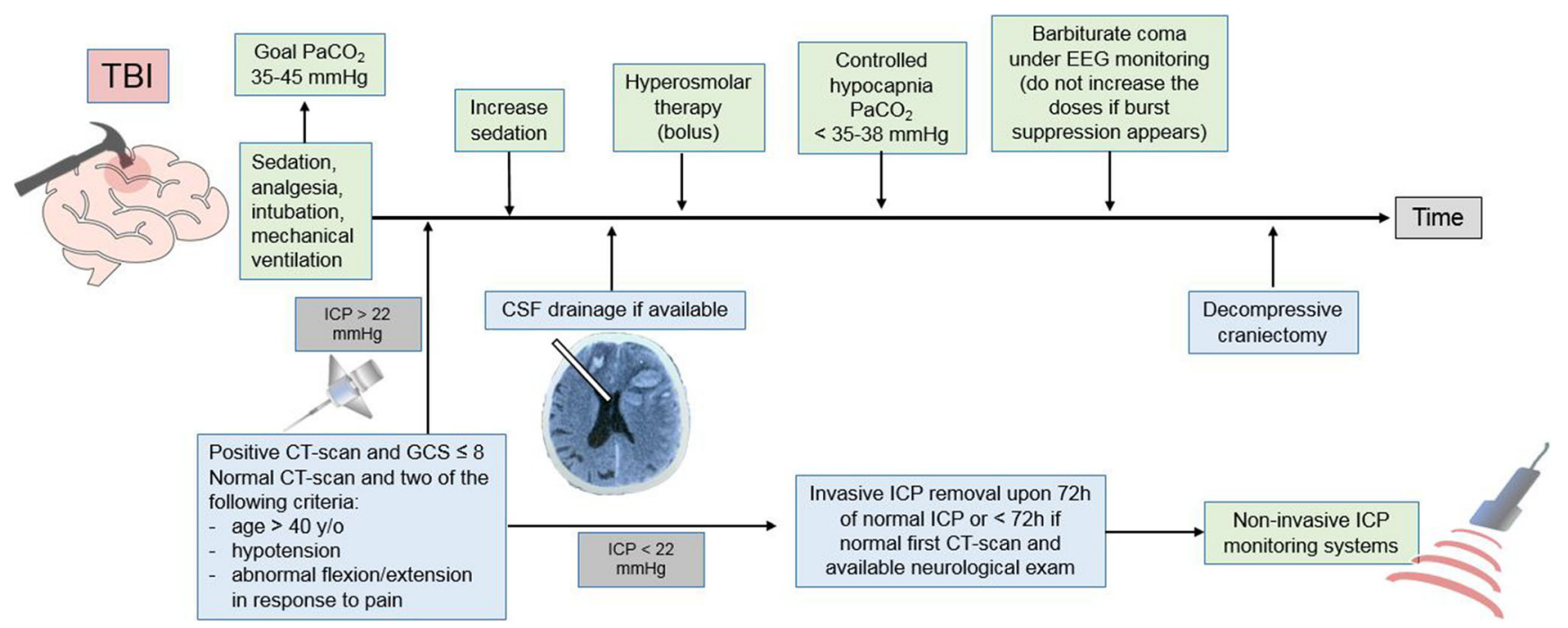

Fig. 1 Indications for invasive ICP (I-ICP) monitoring and staircase approach in case of refractory intracranial hypertension, consisting in a step-by-step escalation therapy 
Fig. 2 Search methodology and results on Medline database

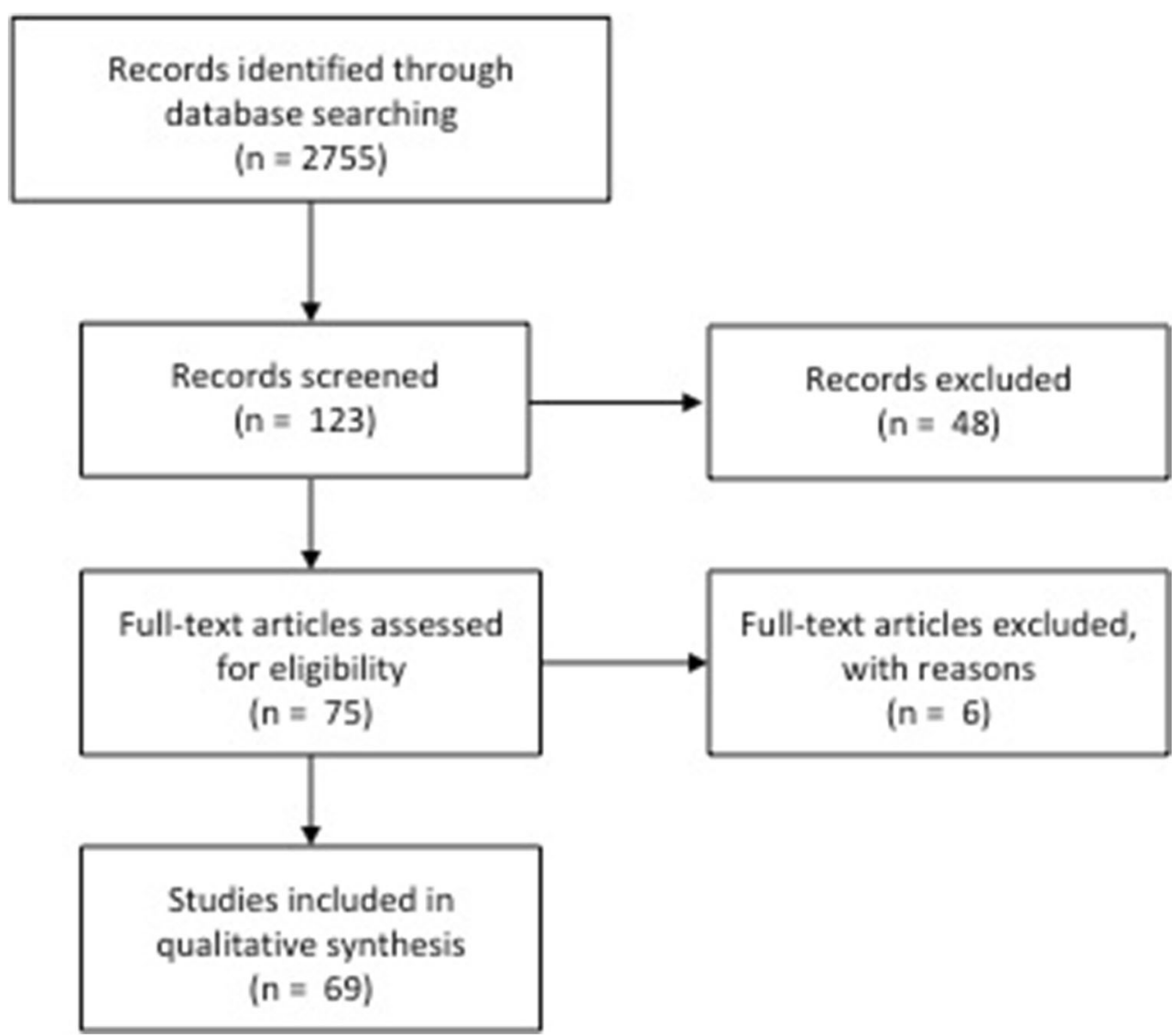

useful technique to effectively decrease ICP, although there are no current evidences supporting its general use in TBI patients because of unproven clinical benefit [10, 12, 15]. The final step of the medical therapy for ICP treatment is represented by barbiturates, which depress the cerebral metabolism reducing $\mathrm{CBF}$ and ICP. Barbiturate administration is characterized by potentially damaging side effects like cardiac depression, hypotension, and risk of infection, thereby making its use reserved for refractory intracranial hypertension [53, 63]. High-dose barbiturate therapy is generally started after a demonstrated response to a test dose. Moreover, electroencephalographic (EEG) monitoring during barbiturates infusion should be available, and further increases of the dose must be avoided if burst suppression is reached. Of note, the primary endpoint of barbiturate therapy is ICP control and not burst suppression, because of dose-related toxicity [27]. Decompressive craniectomy (DC) represents the ultimate treatment for refractory intracranial hypertension, and its efficacy in controlling ICP has been largely demonstrated [10, 16, 27, 29, 59, 61, 62]. Two major multicenter randomized controlled trials aimed to compare decompressive craniectomy with medical management [16, 29]. The Decompressive Craniectomy (DECRA) trial [16] compared bifrontal decompressive craniectomy with maximal medical treatment in diffuse TBI with ICP $>20 \mathrm{mmHg}$ for $15 \mathrm{~min}$ or longer, observing similar mortality in the two groups, with a rate of unfavorable neurologic outcomes significantly higher for surgical patients. Likewise, the Randomized Evaluation of Surgery with Craniectomy for Uncontrollable Elevation of Intracranial Pressure (RESCUEicp) study [29] compared medical therapy with decompressive craniectomy in patients with ICP $>25 \mathrm{mmHg}$ for more than 1-12 $\mathrm{h}$ and resistant to initial medical therapy. Decompressive craniectomy resulted in lower mortality and higher rates of vegetative state, lower severe disability, and upper severe disability at 6 months, with similar rate of moderate disability and good recovery in respect to the medical group. The results of RESCUEicp should be interpreted referring to the implications related to an increased number of vegetative state and increased number of patients with less severe disability. Moreover, the indication for DC should involve the assessment of priorities, modulating the medical choice to the socio-economical contexts.

Several meta-analyses on DC in TBI population and its effects on long-term outcome are available in literature [20, $22,24,37,45,55,65,68,69]$. All these studies demonstrated the efficacy of DC in controlling ICP, reducing mortality and hospital length-of-stay, with an increased rate of unfavorable outcome when compared with medical treatment.

Sahuquillo et al. [55] performed a meta-analysis on three randomized trials on 590 severe TBI patients assessing the 
effects of decompressive craniectomy on outcome. Authors confirmed that DC reduces mortality, determining heterogenic effects on long-term neurological outcome. Besides, they concluded that further studies focusing on the clinical and radiological prognostic factors implicated in survival and acceptable quality of life should be performed.

\section{Invasive ICP monitoring}

The first monitoring tool for ICP was introduced by Guillaume [25] and Lundberg [38], referring to an external ventricular drainage connected to a transducer measuring ICP. The knowledge of ICP values in severe TBI is mandatory to direct care, although its influence on outcome is still not well known because of the lack of well conducted randomized controlled trials [10, 13]. A systematic review [13] tried to clarify the rational for I-ICP monitoring, showing that there are no strong evidences on outcome between patients with or without ICP monitoring. However, a large amount of observational data suggests that ICP monitoring and management can have a beneficial effect on long-term outcome. I-ICP monitoring is suggested for patients with traumatic brain injury and abnormalities on CT scan in whom neurological examination is not available, as well as in patients with a normal CT scan and two or more of the following criteria: age $>40$ years, hypotension, and abnormal flexion/extension in response to pain, but the choice of placing an I-ICP should be weighted on each individual case [10,13]. Many studies tried to repurpose the invasive ICP monitoring, showing a similar [17] or worse outcome [58] in patients with monitoring compared to those without. The only large multicenter randomized controlled trial available was published in 2012 [14] and it did not show any advantage on outcome in patients with I-ICP monitoring in comparison to those with only imaging and clinical examinations. In addition, this study did not discuss the occurrence of serious catheter-related adverse events [14]. However, several criticisms have been raised on this study, some related to its design, while others to the inadequate sample size and the randomization criteria. Besides, this study highlighted the need for a correct interpretation of I-ICP monitoring, promoting the role of novel alternative non-invasive monitoring systems. In summary, it is not the ICP monitoring per se, but instead is the information obtained from ICP monitoring that affects outcome. In fact, the improvement of outcome should result from different therapeutic choices guided by ICP monitoring, and not from the monitoring alone. To better define this concept, the Brain Trauma Foundation [10] highlight the fact that, in absence of clear evidence, the decision to insert an invasive I-ICP monitoring should be considered case by case $[59,62]$. A main concern is the definition of an initial abnormal CT scan, because a small amount of blood within the subarachnoid space may not be considered a pathological
CT scan. In fact, the Milan Consensus Conference [62] did not recommend I-ICP monitoring in comatose patients with normal CT scan or with initial evidence of minimal signs of injury (subarachnoid hemorrhage or petechiae). In these cases, a second CT scan is indicated, in order to exclude a worsening of the initial radiological findings [62]. Moreover, since the standardization of guidelines for each individual patient is not reliable and feasible in clinical practice, no specific indications for the positioning of I-ICP monitoring have been reported in the last Consensus Conference and in the new edition of Brain Trauma Foundation Guidelines, leaving the choice to the clinical experience $[10,47]$.

\section{Complications of invasive ICP monitoring}

Although invasive ICP monitoring placement is considered a minor and safe surgery, complications could be potentially devastating. Table 1 summarizes possible complications of I-ICP monitoring. Hemorrhage rates are not well characterized, mainly due to the different definitions of hemorrhage across different studies [5, 7, 19, 23, 26, 34, 39, 64]. Gelabert-Gonzalez et al. [23] found an overall bleeding rate of $2.5 \%$ (25 patients) and 6 of them required surgical evacuation (4 intraparenchymal hemorrhages, 2 epidural hematomas). Interestingly, postoperative bleeding rate was $1.9 \%$ in patients without coagulopathy and $8 \%$ in patients with at least 1 abnormal coagulation parameter. Irrespective of its retrospective design, the results of this study should be taken into account because the use of antithrombotic drugs is increasing worldwide [21]. Two meta-analyses on intracranial hemorrhage caused by external ventricular drainage (EVD) placemen $\mathrm{t}[5,7]$ observed significant hemorrhage in $0.7 \%$ and $0.61 \%$, despite a higher cumulative rate of bleeding. The complications related to the placement of ICP probe are justified by the "state of need," whereas the complications related to infections result more controllable because of their correlation with ICP probe maintenance and management [64].

Infection is the most common complication that significantly affects patients' outcome in terms of mortality, morbidity, length of stay, and cost of care [41]. In 1984, Mayhall et al. [39] reported an unacceptable cumulative rate of infection 5 days after the ICP ventricular monitoring, but the daily risk of monitoring was not reported. To date, the devices used for I-ICP monitoring are technologically different, and a use time longer than 5 days is guaranteed by manufacturing companies. Kanter et al. [30] retrospectively reviewed data on I-ICP monitoring observing a daily infection rate of $1.5 \%$, with a cumulative risk of $6 \%$ on day $5,16 \%$ on day 9 , and $21 \%$ on day 11 . They observed a higher risk of infection within the first week, with a subsequent fall after day 6 , suggesting that the infection is usually related to the insertion of ICP probe. In the study of Chatzi et al. on EVD, which can be considered equivalent to 
Table 1 Complications associated with invasive ICP monitoring and EVD placement

\begin{tabular}{|c|c|c|c|c|c|}
\hline Author & No. of patients & Type of study & Hemorrhage $(\%)$ & Infection $(\%)$ & Technical problems \\
\hline Dimitriou et al. [15] & 288 & Retrospective & $\begin{array}{l}3 / 296(1.01) \\
2 / 173(1.16) * \\
1 / 123(0.8)^{\circ}\end{array}$ & $\begin{array}{l}16 / 173(9.2)^{*} \\
1 / 123(0.8)^{\circ}\end{array}$ & NR \\
\hline Koskinen et al. [29] & 549 & Retrospective & $27 / 549(4.9 \%)$ & NR & NR \\
\hline Gelabert-González et al. [19] & 1000 & Retrospective & $25 / 1000(2.5)$ & $46 / 547(8.5)$ & $49 / 1000(4.9)$ \\
\hline Chatzi et al. [7] & 139 & Retrospective & NR & $\begin{array}{l}\text { Pre-education } 23 / 82(28)^{*} \\
\text { Post-education } 6 / 57(10.5)^{*}\end{array}$ & NR \\
\hline Park et al. [37] & 595 & Retrospective & NR & $51 / 595(8.6)^{*}$ & NR \\
\hline Holloway et al. [24] & 584 & Retrospective & NR & $\begin{array}{l}61 / 584(10.4)^{*} \\
1^{\circ} \text { catheter } 50 / 584(8.6) \\
2^{\circ} \text { catheter } 10 / 92(10.9) \\
3^{\circ} \text { catheter } 1 / 19(5.3)\end{array}$ & NR \\
\hline Kanter et al. [26] & 65 & Retrospective & NR & $9 / 72(12.5)$ & NR \\
\hline Schürer et al. [48] & 95 & Prospective & NR & NR & $24 / 95(25.3)$ \\
\hline Guyot et al. [22] & 536 & Retrospective & $\begin{array}{l}15 / 536(2.8) \\
13 / 274(4.7)^{*} \\
2 / 262(0.8)^{\circ}\end{array}$ & $\begin{array}{l}21 / 536(3.9) \\
20 / 274(7.3)^{*} \\
1 / 262(0.38)\end{array}$ & NR \\
\hline Mayhall et al. [33] & 172 & Prospective & $19 / 213(8.9)^{*}$ & NR & NR \\
\hline Lozier et al:[30] & 5261 & Meta-analysis & NR & $463 / 5733(8.08)^{*}$ & NR \\
\hline Bauer et al. [3] & NR & Meta-analysis & $203 / 2428(8.4)^{*}$ & NR & NR \\
\hline Binz et al. [4] & NR & Meta-analysis & $102 / 1790(5.7)$ & NR & NR \\
\hline
\end{tabular}

$N R$ not reported

*EVD catheters

${ }^{\circ}$ Other devices

the intraventricular ICP device, the authors showed that the application of a protocol, including education of the personnel, meticulous handling of the EVD, minimization of CSF sampling, and routine replacement of the catheter on day 7 , induced the drop in rates of associated infections from 28 to $10.5 \%$ [11].

Assuming the fact that I-ICP monitoring carries the risk of infection, the real impact of a longer duration of probe maintenance on its incidence remains debated. Lozier et al. [36] observed a rate of $0-22 \%$; however, considering data from the 23 major studies included in the final analysis only, the authors found an overall incidence of $8.8 \%$ /patient and 8.08/ EVD placement.

Park et al. [44] found that the rate of infections reached a peak at day 4, while Holloway et al. found that the rate of infections steadily increased until day 10 [28]. The use of IICP monitoring is largely recommended in TBI and aneurysmal SAH but its removal should be performed as soon as possible, weighing the therapeutic benefits of continued monitoring versus the risk of infection.

The duration of I-ICP monitoring carries at least two other concerns. The first is related to the risk of inaccurate readings. In fact, that some bolts could drift is known [3, 23], resulting in progressive imprecise analysis and inaccurate readings [2]. Other technical complications include breakage of the optical fibers, dislocation of the fixation screw or the probe, and failure of ICP recording for unknown reasons. The rate of I-ICP monitoring technical problems ranges from 4.5 to $25 \%$ [2, 23, 57], according to the fact that most of these complications occurred during nursing maneuvers, transport of the patient, or patient's activity. In light of these, it seems reasonable that the risk of a technical problem varies directly with the length of I-ICP monitoring.

In case of intraventricular pressure monitoring devices, obstruction of the ventriculostomy catheter represents another issue. This problem is often caused by cellular debris, such as blood clots and/or tissue fragments. Mechanical EVD failure, such as kinking of the device, failure of any part of the system, migration of EVD catheter, and physiologic factors such as over drainage or tight ventricles and/or CSF leak, may also result in obstruction [33, 40]. Dampening of the ICP waveform, reduction or absence of CSF flow, and lack of pulsation of the CSF meniscus of the drain tube during respiration can ultimately result in catheter obstruction. If mechanical failure is suspected, the EVD collection system should be substituted, whereas if cellular debris is suspected, catheter irrigation using a small volume (less than $2 \mathrm{ml}$ ) of sterile isotonic normal saline should be performed under strict sterile conditions to restore the flow $[18,26]$. As stated above for technical complications, the risk of EVD blockage also seems 
influenced by the duration of EVD placement. Besides, intraventricular I-ICP device is considered the gold standard for intracranial compliance evaluation, although it is related to a potential higher rate of complications such as infection, hemorrhage, and technical problems $[2,5,6,8,23,56,57]$ that require a careful management of the device during ICU stay. The antibiotic and silver impregnated catheters, the use of intraventricular catheter for less than 5 days, and the positioning with sterile techniques in the operating room have shown a reduction of infection rate [7]. Furthermore, ventricular I-ICP monitoring systems are difficult to position in younger patient because of the smaller ventricle volume, and in some TBI patients whose intracranial hypertension has caused the collapse of their ventricular system [42]. Although intraventricular monitoring is considered the gold standard for ICP management, studies comparing this type of monitoring with other devices have shown variable results $[1,31,35,66]$. A recent study analyzed the outcome of TBI patients with intraventricular monitoring and intraparenchymal devices, finding a significantly higher mortality, and worse neurological and neuropsychological outcome in case of early positioning of intraventricular device in comparison to intraparenchymal monitoring [4].

\section{I-ICP monitoring weaning}

A common question raised in clinical practice is how long to maintain I-ICP monitoring in non-neurologically detectable patients. The literature is very poor on this theme, and clinicians have to consider the risk/benefit ratio to decide when IICP monitoring removal could be indicated. The complications related to the length of device monitoring have to be considered [5, 30, 32, 48, 49, 64, 67] (Table 1). In the study of Kanter et al. [30], ICP monitoring was maintained for less than 7 days but no more than 28 days in half of cases. Picard et al. [46], in a retrospective multicenter international survey, reported the maintenance of ICP monitoring probe for 7 days in TBI patients. By contrast, Winfield et al. [67] did not describe a positive correlation between the duration of I-ICP monitoring and the rate of daily infection, reporting 2 weeks as the maximal period of monitoring. They concluded that the decision to remove I-ICP monitoring should be based only on the necessity to continually observe the ICP values. In the Seattle International Severe Traumatic Brain Injury Consensus [12, 27], the theme of I-ICP monitoring weaning was analyzed. A heat map to guide decision-making based on ICP values for definite periods (for $24 \mathrm{~h}, 48 \mathrm{~h}, 72 \mathrm{~h},>72 \mathrm{~h}$ ), the CT scan classification, the presence of evacuated mass lesion, and the line of therapy used to treat intracranial hypertension [10] were carried out. In conclusion, they decided that $72 \mathrm{~h}$ of acceptable ICP values should be considered for monitoring removal, whereas removal after $24 \mathrm{~h}$ is recommended only for cases with a benign CT scan and an acceptable neurological evaluation.

Summarizing, there is no universal consensus about the relation between duration of I-ICP monitoring and complications, but the review of the pertinent literature strongly suggests that a longer period of I-ICP monitoring portends a higher risk of technical problems. Therefore, clinicians have to consider the risk/benefit ratio of I-ICP monitoring maintenance, and the necessity of continual observation of ICP values. The therapeutic aggressiveness to obtain ICP control could also influence the decision to remove I-ICP monitoring.

\section{The role of non-invasive ICP monitoring}

Invasive ICP monitoring is considered the standard of care after severe TBI [10]. Severe complications have been observed during I-ICP monitoring, thereby limiting its use to those patients who fully meet the selection criteria. Therefore, the search for non-invasive ICP monitoring to replace the invasive assessment started many years ago [51]. Several non-invasive methods have been proposed, and the methods based on ultrasounds such as transcranial Doppler (TCD) or optic nerve sheath diameter (ONSD) gained more popularity for their safety, availability, and reliability characteristics [51]. Actually, non-invasive ICP monitoring is divided into the following: (1) imagine techniques such as magnetic resonance, tomography scan, and ONSD; (2) indirectly transmitted ICP such as TCD and eyeball ophthalmic artery method; (3) monitoring of metabolic alterations such as nearinfrared spectroscopy; and (4) registration of functional activity such as electroencephalography, visual-evoked potential, and acoustic potential [50]. Of note, the ideal non-invasive monitoring method should be easily performed, suitable in emergency setting, operator-independent, risk free, accurate, precise, and low cost. The main advantages of non-invasive monitoring systems are the potential multiple times reproducibility without further costs, the bilateralism of the assessments, and the low risk of complications [50]. Disadvantages include insufficient accuracy, operator-dependency, and the difficult clinical applicability in some cases, thus suggesting that non-invasive monitoring systems are not efficacious enough to substitute invasive ICP measurement [50]. Besides, an accurate method available in literature is represented by 2-depth-high-resolution-transcranial Doppler insonation of the ophthalmic artery, which allows to select the intersection point for which the blood flow velocity waveform in the intracranial segment of the ophthalmic artery is equal to the blood flow velocity of the extracranial vessel. Robba et al. recently assessed an observational study on the ultrasound non-invasive measurement of ICP, demonstrating that ONSD and straight sinus systolic flow velocity $\left(\mathrm{FV}_{\mathrm{SV}}\right)$ have a good correlation with ICP, whereas the mean arterial 
carotid pulsatility index and the estimator based on diastolic flow velocity $\left(\mathrm{FV}_{\mathrm{d}}\right)$ did not correlate with ICP [51]. Although the search for the most accurate non-invasive monitoring system is still ongoing, ultrasound-based methods have been proved to guarantee an acceptable accuracy [9]. In summary, we suggest the application of these novel non-invasive ICP neuromonitoring methods in those TBI patients where an invasive ICP probe is contraindicated or those at high risk for invasive ICP monitoring-related complications. Moreover, continuous monitoring with less invasive measures should follow invasive probe removal in order to guarantee adequate monitoring in the early weaning phase from the invasive ICP monitoring [52].

\section{Conclusions}

Nowadays, I-ICP monitoring represents a standard of care in patients with TBI and abnormal CT scan in whom neurological evaluation is not feasible, as well as in those patients with normal CT scan and risk factors for secondary brain injury $[10,62]$. The risks of I-ICP monitoring-related complications are related not only to its insertion maneuver, but also to the duration of maintenance, as confirmed by most of the records found in the present review. Considering both the possible issues related to monitoring duration, and the clinical conditions that could guide the clinicians, I-ICP monitoring removal is justified after $72 \mathrm{~h}$ of normal ICP values, or earlier if the first CT scan is normal and the neurological exam is viable. Moreover, the availability of non-invasive monitoring systems should be considered to follow the patient's clinical course after ICP probe removal, or for substituting the invasive monitoring in the event of contraindication to invasive monitoring.

\section{Compliance with ethical standards}

Conflict of interest The authors declare that they have no conflict of interest.

Informed consent Not applicable.

\section{References}

1. Aiolfi A, Khor D, Cho J, Benjamin E, Inaba K, Demetriades D (2018) Intracranial pressure monitoring in severe blunt head trauma: does the type of monitoring device matter? J Neurosurg 128: 828-833. https://doi.org/10.3171/2016.11.JNS162198

2. Al-Tamimi YZ, Helmy A, Bavetta S, Price SJ (2009) Assessment of zero drift in the Codman intracranial pressure monitor: a study from 2 neurointensive care units. Neurosurgery 64:94-98; discussion 98-9. https://doi.org/10.1227/01.NEU.0000328392.98602.5A

3. Allin D, Czosnyka M, Czosnyka Z (2008) Laboratory testing of the Pressio intracranial pressure monitor. Neurosurgery 62:1158-1161; discussion 1161. https://doi.org/10.1227/01.neu.0000325878. 67752.eb

4. Bales JW, Bonow RH, Buckley RT, Barber J, Temkin N, Chesnut RM (2019) Primary external ventricular drainage catheter versus intraparenchymal ICP monitoring: outcome analysis. Neurocrit Care 31:11-21. https://doi.org/10.1007/s12028-019-00712-9

5. Bauer DF, Razdan SN, Bartolucci AA, Markert JM (2011) Metaanalysis of hemorrhagic complications from ventriculostomy placement by neurosurgeons. Neurosurgery 69:255-260. https://doi.org/ 10.1227/NEU.0b013e31821a45ba

6. Bhatia A, Gupta AK (2007) Neuromonitoring in the intensive care unit. I. Intracranial pressure and cerebral blood flow monitoring. Intensive Care Med 33:1263-1271. https://doi.org/10.1007/ s00134-007-0678-z

7. Binz DD, Toussaint LG, Friedman JA (2009) Hemorrhagic complications of ventriculostomy placement: a meta-analysis. Neurocrit Care 10:253. https://doi.org/10.1007/s12028-009-9193-0

8. Bratton SL, Chestnut RM, Ghajar J, McConnell Hammond FF, Harris OA, Hartl R, Manley GT, Nemecek A, Newell DW, Rosenthal G, Schouten J, Shutter L, Timmons SD, Ullman JS, Videtta W, Wilberger JE, Wright DW (2007) Intracranial pressure monitoring technology. J Neurotrauma 24:S-45-S-54. https://doi. org/10.1089/neu.2007.9989

9. Cardim D, Robba C, Czosnyka M, Savo D, Mazeraud A, Iaquaniello C, Banzato E, Rebora P, Citerio G (2019) Noninvasive intracranial pressure estimation with transcranial Doppler. J Neurosurg Anesthesiol 1. https://doi.org/10.1097/ ANA.0000000000000622

10. Carney N, Totten AM, O'Reilly C, Ullman JS, Hawryluk GWJ, Bell MJ, Bratton SL, Chesnut R, Harris OA, Kissoon N, Rubiano AM, Shutter L, Tasker RC, Vavilala MS, Wilberger J, Wright DW, Ghajar J (2017) Guidelines for the management of severe traumatic brain injury, Fourth Edition. Neurosurgery 80:6-15. https://doi.org/ 10.1227/NEU.0000000000001432

11. Chatzi M, Karvouniaris M, Makris D, Tsimitrea E, Gatos C, Tasiou A, Mantzarlis K, Fountas KN, Zakynthinos E (2014) Bundle of measures for external cerebral ventricular drainage-associated ventriculitis. Crit Care Med 42:66-73. https://doi.org/10.1097/ CCM.0b013e31829a70a5

12. Chesnut R, Aguilera S, Buki A, Bulger E, Citerio G, Cooper DJ, Arrastia RD, Diringer M, Figaji A, Gao G, Geocadin R, Ghajar J, Harris O, Hoffer A, Hutchinson P, Joseph M, Kitagawa R, Manley G, Mayer S, Menon DK, Meyfroidt G, Michael DB, Oddo M, Okonkwo D, Patel M, Robertson C, Rosenfeld JV, Rubiano AM, Sahuquillo J, Servadei F, Shutter L, Stein D, Stocchetti N, Taccone FS, Timmons S, Tsai E, Ullman JS, Vespa P, Videtta W, Wright DW, Zammit C, Hawryluk GWJ (2020) A management algorithm for adult patients with both brain oxygen and intracranial pressure monitoring: the Seattle International Severe Traumatic Brain Injury Consensus Conference (SIBICC). Intensive Care Med. https://doi. org/10.1007/s00134-019-05900-x

13. Chesnut R, Videtta W, Vespa P, Le Roux P, Participants in the International Multidisciplinary Consensus Conference on Multimodality Monitoring (2014) Intracranial pressure monitoring: fundamental considerations and rationale for monitoring. Neurocrit Care 21(Suppl 2):S64-S84. https://doi.org/10.1007/s12028-0140048-y

14. Chesnut RM, Temkin N, Carney N, Dikmen S, Rondina C, Videtta W, Petroni G, Lujan S, Pridgeon J, Barber J, Machamer J, Chaddock K, Celix JM, Cherner M, Hendrix T, Global Neurotrauma Research Group (2012) A trial of intracranialpressure monitoring in traumatic brain injury. N Engl J Med 367: 2471-2481. https://doi.org/10.1056/NEJMoa1207363

15. Clifton GL, Valadka A, Zygun D, Coffey CS, Drever P, Fourwinds S, Janis LS, Wilde E, Taylor P, Harshman K, Conley A, Puccio A, Levin HS, McCauley SR, Bucholz RD, Smith KR, Schmidt JH, 
Scott JN, Yonas H, Okonkwo DO (2011) Very early hypothermia induction in patients with severe brain injury (the National Acute Brain Injury Study: Hypothermia II): a randomised trial. Lancet Neurol 10:131-139

16. Cooper DJ, Rosenfeld JV, Murray L, Arabi YM, Davies AR, D’Urso P, Kossmann T, Ponsford J, Seppelt I, Reilly P, Wolfe R, DECRA Trial Investigators, Australian and New Zealand Intensive Care Society Clinical Trials Group (2011) Decompressive craniectomy in diffuse traumatic brain injury. N Engl J Med 364: 1493-1502. https://doi.org/10.1056/NEJMoa1102077

17. Cremer OL, Van Dijk GW, Van Wensen E, Brekelmans GJF, Moons KGM, Leenen LPH, Kalkman CJ (2005) Effect of intracranial pressure monitoring and targeted intensive care on functional outcome after severe head injury. Crit Care Med 33:2207-2213

18. Dey M, Jaffe J, Stadnik A, Awad IA (2012) External ventricular drainage for intraventricular hemorrhage. Curr Neurol Neurosci Rep 12:24-33. https://doi.org/10.1007/s11910-011-0231-x

19. Dimitriou J, Levivier M, Gugliotta M (2016) Comparison of complications in patients receiving different types of intracranial pressure monitoring: a retrospective study in a single center in Switzerland. World Neurosurg 89:641-646. https://doi.org/10. 1016/j.wneu.2015.11.037

20. Fatima N, Al Rumaihi G, Shuaib A, Saqqur M (2019) The role of decompressive craniectomy in traumatic brain injury: a systematic review and meta-analysis. Asian J Neurosurg 14:371. https://doi. org/10.4103/ajns.AJNS 28918

21. Fiaschi P, Iaccarino C, Stefini R, Prior E, Prior A, Zona G (2020) Clinical practice for antiplatelet and anticoagulant therapy in neurosurgery: data from an Italian survey and summary of current recommendations - part I, antiplatelet therapy. Neurosurg Rev. https://doi.org/10.1007/s10143-019-01229-7

22. Garg K, Singh P, Singla R, Aggarwal A, Borle A, Singh M, Ps C, Kale S, Mahapatra A (2019) Role of decompressive craniectomy in traumatic brain injury-a meta-analysis of randomized controlled trials. Neurol India 67:1225. https://doi.org/10.4103/0028-3886. 271260

23. Gelabert-González M, Ginesta-Galan V, Sernamito-García R, Allut AG, Bandin-Diéguez J, Rumbo RM (2006) The Camino intracranial pressure device in clinical practice. Assessment in a 1000 cases. Acta Neurochir 148:435-441. https://doi.org/10.1007/s00701-0050683-3

24. Grindlinger GA, Skavdahl DH, Ecker RD, Sanborn MR (2016) Decompressive craniectomy for severe traumatic brain injury: clinical study, literature review and meta-analysis. Springerplus 5: 1605. https://doi.org/10.1186/s40064-016-3251-9

25. Guillaume J, Janny P (1951) Continuous intracranial manometry; importance of the method and first results. Rev Neurol 84:131-142

26. Guyot LL, Dowling C, Diaz FG, Michael DB (1998) Cerebral monitoring devices: analysis of complications. In: Intracranial pressure and neuromonitoring in brain injury. Springer Vienna, Vienna, pp 47-49

27. Hawryluk GWJ, Aguilera S, Buki A, Bulger E, Citerio G, Cooper DJ, Arrastia RD, Diringer M, Figaji A, Gao G, Geocadin R, Ghajar J, Harris O, Hoffer A, Hutchinson P, Joseph M, Kitagawa R, Manley G, Mayer S, Menon DK, Meyfroidt G, Michael DB, Oddo M, Okonkwo D, Patel M, Robertson C, Rosenfeld JV, Rubiano AM, Sahuquillo J, Servadei F, Shutter L, Stein D, Stocchetti N, Taccone FS, Timmons S, Tsai E, Ullman JS, Vespa P, Videtta W, Wright DW, Zammit C, Chesnut RM (2019) A management algorithm for patients with intracranial pressure monitoring: the Seattle International Severe Traumatic Brain Injury Consensus Conference (SIBICC). Intensive Care Med 45:17831794. https://doi.org/10.1007/s00134-019-05805-9

28. Holloway KL, Barnes T, Choi S, Bullock R, Marshall LF, Eisenberg HM, Jane JA, Ward JD, Young HF, Marmarou A (1996) Ventriculostomy infections: the effect of monitoring duration and catheter exchange in 584 patients. J Neurosurg 85: 419-424. https://doi.org/10.3171/jns.1996.85.3.0419

29. Hutchinson PJ, Kolias AG, Timofeev IS, Corteen EA, Czosnyka M, Timothy J, Anderson I, Bulters DO, Belli A, Eynon CA, Wadley J, Mendelow AD, Mitchell PM, Wilson MH, Critchley G, Sahuquillo J, Unterberg A, Servadei F, Teasdale GM, Pickard JD, Menon DK, Murray GD, Kirkpatrick PJ, RESCUEicp Trial Collaborators (2016) Trial of decompressive craniectomy for traumatic intracranial hypertension. N Engl J Med 375:1119-1130. doi: https://doi.org/10.1056/NEJMoa1605215

30. Kanter RK, Weiner LB, Patti AM, Robson LK (1985) Infectious complications and duration of intracranial pressure monitoring. Crit Care Med 13:837-839. https://doi.org/10.1097/00003246198510000-00012

31. Kasotakis G, Michailidou M, Bramos A, Chang Y, Velmahos G, Alam H, King D, de Moya MA (2012) Intraparenchymal vs extracranial ventricular drain intracranial pressure monitors in traumatic brain injury: less is more? J Am Coll Surg 214:950-957. https://doi. org/10.1016/j.jamcollsurg.2012.03.004

32. Kiening KL, Schoening WN, Stover JF, Unterberg AW (2003) Continuous monitoring of intracranial compliance after severe head injury: relation to data quality, intracranial pressure and brain tissue PO2. Br J Neurosurg 17:311-318. https://doi.org/10.1080/ 02688690310001601199

33. Kocan MJ (2002) Physicians are asking the nurses to irrigate ventriculostomy catheters. Crit Care Nurse 22:70-73

34. Koskinen L-OD, Grayson D, Olivecrona M (2013) The complications and the position of the Codman MicroSensor ${ }^{\mathrm{TM}}$ ICP device: an analysis of 549 patients and 650 Sensors. Acta Neurochir 155: 2141-2148. https://doi.org/10.1007/s00701-013-1856-0

35. Liu H, Wang W, Cheng F, Yuan Q, Yang J, Hu J, Ren G (2015) External ventricular drains versus intraparenchymal intracranial pressure monitors in traumatic brain injury: a prospective observational study. World Neurosurg 83:794-800. https://doi.org/10. 1016/j.wneu.2014.12.040

36. Lozier AP, Sciacca RR, Romagnoli MF, Connolly ES (2008) Ventriculostomy-related infections. Neurosurgery 62:170-182. https://doi.org/10.1227/01.neu.0000316273.35833.7c

37. Lu G, Zhu L, Wang X, Zhang H, Li Y (2020) Decompressive craniectomy for patients with traumatic brain injury: a pooled analysis of randomized controlled trials. World Neurosurg 133:e135e148. https://doi.org/10.1016/j.wneu.2019.08.184

38. Lundberg N (1960) Continuous recording and control of ventricular fluid pressure in neurosurgical practice. Acta Psychiatr Scand Suppl 36:1-193

39. Mayhall CG, Archer NH, Lamb VA, Spadora AC, Baggett JW, Ward JD, Narayan RK (1984) Ventriculostomy-related Infections. A prospective epidemiologic study. N Engl J Med 310:553

40. Muralidharan R (2015) External ventricular drains: management and complications. Surg Neurol Int 6:271. https://doi.org/10.4103/ 2152-7806.157620

41. Murthy SB, Moradiya Y, Shah J, Hanley DF, Ziai WC (2016) Incidence, predictors, and outcomes of ventriculostomyassociated infections in spontaneous intracerebral hemorrhage. Neurocrit Care 24:389-396. https://doi.org/10.1007/s12028-0150199-5

42. Nag DS, Sahu S, Swain A, Kant S (2019) Intracranial pressure monitoring: gold standard and recent innovations. World J Clin Cases 7:1535-1553. doi: 10.12998/wjcc.v7.i13.1535

43. Olivecrona M, Zetterlund B, Rodling-Wahlström M, Naredi S, Koskinen LO (2009) Absence of electroencephalographic seizure activity in patients treated for head injury with an intracranial pressure-targeted therapy. J Neurosurg 300-5. https://doi.org/10. 3171/2008.4.17538

44. Park P, Garton HJL, Kocan MJ, Thompson BG (2004) Risk of infection with prolonged ventricular catheterization. Neurosurgery 
55:594-601. https://doi.org/10.1227/01.NEU.0000134289.04500. $\mathrm{EE}$

45. Phan K, Moore JM, Griessenauer C, Dmytriw AA, Scherman DB, Sheik-Ali S, Adeeb N, Ogilvy CS, Thomas A, Rosenfeld JV (2017) Craniotomy versus decompressive craniectomy for acute subdural hematoma: systematic review and meta-analysis. World Neurosurg 101:677-685.e2. https://doi.org/10.1016/j.wneu.2017.03.024

46. Picard P, Waleckx P, Bonnard-Gougeon M, Sinardet D, Lemaire JJ, Chazal J (1997) Intracranial pressure monitoring in France, and French-speaking Belgium and Switzerland. Retrospective and prospective survey. Ann Fr Anesth Reanim 16:420-428. https://doi. org/10.1016/s0750-7658(97)81474-8

47. Picetti E, Rossi S, Abu-Zidan FM, Ansaloni L, Armonda R, Baiocchi GL, Bala M, Balogh ZJ, Berardino M, Biffl WL, Bouzat P, Buki A, Ceresoli M, Chesnut RM, Chiara O, Citerio G, Coccolini F, Coimbra R, Di Saverio S, Fraga GP, Gupta D, Helbok R, Hutchinson PJ, Kirkpatrick AW, Kinoshita T, Kluger Y, Leppaniemi A, Maas AIR, Maier RV, Minardi F, Moore EE, Myburgh JA, Okonkwo DO, Otomo Y, Rizoli S, Rubiano AM, Sahuquillo J, Sartelli M, Scalea TM, Servadei F, Stahel PF, Stocchetti N, Taccone FS, Tonetti T, Velmahos G, Weber D, Catena F (2019) WSES consensus conference guidelines: monitoring and management of severe adult traumatic brain injury patients with polytrauma in the first 24 hours. World J Emerg Surg 14:53. https://doi.org/10.1186/s13017-019-0270-1

48. Poca M-A, Sahuquillo J, Arribas M, Báguena M, Amorós S, Rubio E (2002) Fiberoptic intraparenchymal brain pressure monitoring with the Camino V420 monitor: reflections on our experience in 163 severely head-injured patients. J Neurotrauma 19:439-448. https://doi.org/10.1089/08977150252932398

49. Rebuck JA, Murry KR, Rhoney DH, Michael DB, Coplin WM (2000) Infection related to intracranial pressure monitors in adults: analysis of risk factors and antibiotic prophylaxis. J Neurol Neurosurg Psychiatry 69:381-384. https://doi.org/10.1136/jnnp. 69.3.381

50. Robba C, Bacigaluppi S, Cardim D, Donnelly J, Bertuccio A, Czosnyka M (2016) Non-invasive assessment of intracranial pressure. Acta Neurol Scand 134:4-21. https://doi.org/10.1111/ane. 12527

51. Robba C, Cardim D, Tajsic T, Pietersen J, Bulman M, Donnelly J, Lavinio A, Gupta A, Menon DK, Hutchinson PJA, Czosnyka M (2017) Ultrasound non-invasive measurement of intracranial pressure in neurointensive care: a prospective observational study. PLoS Med 14:e1002356. https://doi.org/10.1371/journal.pmed. 1002356

52. Robba C, Goffi A, Geeraerts T, Cardim D, Via G, Czosnyka M, Park S, Sarwal A, Padayachy L, Rasulo F, Citerio G (2019) Brain ultrasonography: methodology, basic and advanced principles and clinical applications. A narrative review. Intensive Care Med 45: 913-927

53. Roberts I, Sydenham E (2012) Barbiturates for acute traumatic brain injury. Cochrane Database Syst Rev 2(12):CD00003. https://doi.org/10.1002/14651858.CD000033.pub2

54. Ropper AH (2012) Hyperosmolar therapy for raised intracranial pressure. N Engl J Med 746-52.

55. Sahuquillo J, Dennis JA (2019) Decompressive craniectomy for the treatment of high intracranial pressure in closed traumatic brain injury. Cochrane Database Syst Rev 12:CD003983. https://doi. org/10.1002/14651858.CD003983.pub3

56. Saladino A, White JB, Wijdicks EFM, Lanzino G (2009) Malplacement of ventricular catheters by neurosurgeons: a single institution experience. Neurocrit Care 10:248-252. https://doi.org/ 10.1007/s12028-008-9154-Z

57. Schürer L, Münch E, Piepgras A, Weigel R, Schilling L, Schmiedek P (1997) Assessment of the CAMINO intracranial pressure device in clinical practice. Acta Neurochir Suppl 70:296-298. https://doi. org/10.1007/978-3-7091-6837-0_92

58. Shafi S, Diaz-Arrastia R, Madden C, Gentilello L (2008) Intracranial pressure monitoring in brain-injured patients is associated with worsening of survival. J Trauma 64:335-340

59. Stocchetti N, Longhi L, Zanier ER (2008) Intracranial pressure monitoring for traumatic brain injury: available evidence and clinical implications. Minerva Anestesiol 74:197-203

60. Stocchetti N, Maas AI, Chieregato A, Van der Plas AA (2005) Hyperventilation in head injury: a review. Chest 127:1812-1827

61. Stocchetti N, Maas AIR (2014) Traumatic intracranial hypertension. N Engl J Med 370:2121-2130. https://doi.org/10.1056/ NEJMra1208708

62. Stocchetti N, Picetti E, Berardino M, Buki A, Chesnut RM, Fountas KN, Horn P, Hutchinson PJ, Iaccarino C, Kolias AG, Koskinen LO, Latronico N, Maas AIR, Payen J-F, Rosenthal G, Sahuquillo J, Signoretti S, Soustiel JF, Servadei F (2014) Clinical applications of intracranial pressure monitoring in traumatic brain injury: report of the Milan consensus conference. Acta Neurochir 156:1615-1622. https://doi.org/10.1007/s00701-014-2127-4

63. Stocchetti N, Zanaboni C, Colombo A, Citerio G, Beretta L, Ghisoni L, Zanier ER, Canavesi K (2008) Refractory intracranial hypertension and "second-tier" therapies in traumatic brain injury. Intensive Care Med 34:461-467

64. Tavakoli S, Peitz G, Ares W, Hafeez S, Grandhi R (2017) Complications of invasive intracranial pressure monitoring devices in neurocritical care. Neurosurg Focus 43:1-9. https://doi.org/10. 3171/2017.8.FOCUS17450

65. Tsaousi GG, Marocchi L, Sergi PG, Pourzitaki C, Santoro A, Bilotta F (2020) Early and late clinical outcomes after decompressive craniectomy for traumatic refractory intracranial hypertension: a systematic review and meta-analysis of current evidence. J Neurosurg Sci 64. https://doi.org/10.23736/S0390-5616.18.04527-7

66. Volovici V, Huijben JA, Ercole A, Stocchetti N, Dirven CMF, van der Jagt M, Steyerberg EW, Lingsma HF, Menon DK, Maas AIR, Haitsma IK (2019) Ventricular drainage catheters versus intracranial parenchymal catheters for intracranial pressure monitoring-based management of traumatic brain injury: a systematic review and meta-analysis. J Neurotrauma 36:988-995. https://doi.org/10. 1089/neu.2018.6086

67. Winfield JA, Rosenthal P, Kanter RK, Casella G (1993) Duration of intracranial pressure monitoring does not predict daily risk of infectious complications. Neurosurgery 33:424-430; discussion 430-1. https://doi.org/10.1227/00006123-199309000-00011

68. Zhang D, Xue Q, Chen J, Dong Y, Hou L, Jiang Y, Wang J (2017) Decompressive craniectomy in the management of intracranial hypertension after traumatic brain injury: a systematic review and meta-analysis. Sci Rep 7:8800. https://doi.org/10.1038/s41598017-08959-y

69. Zhang K, Jiang W, Ma T, Wu H (2016) Comparison of early and late decompressive craniectomy on the long-term outcome in patients with moderate and severe traumatic brain injury: a meta-analysis. Br J Neurosurg 30:251-257. https://doi.org/10.3109/ 02688697.2016 .1139052

Publisher's note Springer Nature remains neutral with regard to jurisdictional claims in published maps and institutional affiliations. 